\title{
Erkek Güreş Hakemlerinin Öfke ve Kızgınlık Düzeyleri ile Empatik Eğilim Gösterme Düzeyleri Arasındaki İlişkinin Çeşitli Değisskenlere Göre İncelenmesi
}

\author{
Melike ESENTAŞ ${ }^{* 1}$, Nevzat DİNÇER ${ }^{1}$, Enes IŞIKGÖZ ${ }^{1}$, Ertan ÇELIIK $^{\mathbf{2}}$ \\ ${ }^{1}$ Batman Üniversitesi, Beden Eğitimi ve Spor Yüksekokulu \\ ${ }^{2}$ Batman Üniversitesi, Rekreasyon Yönetimi Anabilim Dalı
}

$\ddot{O} z$

Orijinal Makale

Bu çalışmanın amacı erkek güreş hakemlerinin öfke ve kızgınlık düzeyleri ile empatik eğilim gösterme düzeylerinin incelenmesidir. Çalışmanın grubunu 27-30 Aralık 2016 tarihinde Antalya Kemer'de düzenlenen Türkiye Güreş Federasyonu- güreş hakemleri eğitim seminerine katılan 88 erkek güreş hakemi oluşturmaktadır. Araştırmanın verileri Özer (1994) tarafindan Türkçeye uyarlanan "Sürekli Öfke-Öfke Tarz Ölçeği” ile Dökmen (1988) tarafından geliştirilen "Empatik Eğilim Ölçeği” ile toplanmıştır. Verilerin analizinde, betimsel istatistik teknikleri yanı sıra, korelasyon ve çoklu regresyon analizlerinden yararlanılmıştır. Çalışma sonucunda; erkek güreş hakemlerinin öfke ve kızgınlık düzeyleri ile empatik eğilim gösterme düzeyleri arasında anlamlı bir ilişki saptanmamıştır. Ayrıca, hakemlerin medeni durumu, yaşları, eğitim durumları, hakemlik y1lı, hakemlik kategorileri ve başka meslek icra edip etmemeleri, öfke ve kızgınlık düzeyleri ile anlamlı bir ilişki vermemektedir.

\section{An Investigation of the Relationship Between the Levels of Anger and the Levels of Empathy Trends in Male Wrestling Referees by Various Variables}

\begin{abstract}
The aim of this study is to examine the levels of anger and empathic tendencies of male wrestling referees. Working group is composed of 88 male referees participated in the Wrestling Referees Training Seminar organized by Turkey Wrestling Federation held in Antalya Kemer on the date of 27-30 December 2016. The results of the study are collected with "Continuous Anger-Anger Style Scale" adapted by Özer (1994) and "Empathic Tendency Scale" developed by Dökmen (1988). In the analysis of the data, correlation and multiple regression analyzes were used as well as descriptive statistics techniques. In the results of working, there was no significant relationship between levels of anger and empathic tendency of male wrestling referees. In addition, the referees' marital status, age, educational status, refereeing year, refereeing categories and other professions do not give a meaningful relationship with the level of anger.
\end{abstract}

Original Article

Article Info

Received: 01.03.2017

Accepted: 23.04.2017

Online Published: 16.06.2017

Keywords:

Wrestling, referees, empathic tendency, anger, dispositional anger

\section{GíRiş}

Tarihteki en eski sporlardan biri ve geleneksel sporların en önemlisi olan güreşin Türk kültüründe önemli bir yere sahip olunduğu bilinmektedir. Tarihsel olarak Antik Yunan'da oldukça önem verilen güreş sporu, Mısır'da daha önce yapılmış ve sonraki dönemlerde diğer

\footnotetext{
* Sorumlu Yazar:

E-posta: melike.esentas@windowslive.com, +90 5054311386
} 
toplumlara aktarılmıştır (Decker, 1992). Güreş; karş1lıklı iki kişinin hiçbir malzeme ve araç kullanmadan belli kurallar dahilinde belli bir süre ve belli bir alan üzerinde tüm fizyolojik ve psikolojik güçlerini kullanarak birbirlerinin sırtını yere getirme veya teknik üstünlük sağlamak için yapmış oldukları bir mücadeledir (Açak, 2005). Güreş, Büyük Asya'dan Balkanlara tüm Türk dünyası ve akraba toplumlarında bir "onur formu" olarak görülmektedir (Pehlivan ve Demir, 2006: 141-149; Petrov, 1994: 107-108).

Bir güreş müsabakası sırasında güreşin akışını sağlayan ve yapılan oyunları değerlendirenlerde üç kişiden oluşan hakem heyetidir. Bunlardan birisi, minder üzerinde idareyi sağlayıp çeşitli işaretlerle müsabaka sırasındaki hareketlerin değerlendirmesini yaparken diğer ikisi ise minder kenarında müsabakayı izleyerek bu değerlendirmeye kendi fikirleri ile katılarak oyunların en adil ve doğru şekilde değerlendirmesini yapan jüriyi oluşturur (Cicioğlu, 2001). Güreş hakemliği psikolojik ve bilişsel (zihinsel) yönleri olan bir fiziksel eylemdir. Olayın farkına varan hakem çok kısa bir zaman dilimi içerisinde karar vermek durumundadır. Kısaca hakem uyarıcıyı seçerek algılar, analiz eder, kategorilere ayırır, kıyaslama yapar ve daha sonra bu uyarana en uygun tepkiyi verir (Cel, 1994).

Hakemler saha içinde ve saha dışında pek çok baskılara maruz kalmaktadır. Her müsabaka sonrasında günah keçisi ilan edilir, olumlu veya olumsuz her türlü sonuçtan onlar sorumlu tutulur ve en önemlisi kişilikleri hakkında çeşitli yorumlar yapılır. Tüm bu gelişmeler, hakemler üzerinde gerek psikolojik gerekse zihinsel olarak olumsuz etkiler yaratmaktadır (Sülün, 2013). Güreş hakemlerinin de müsabaka öncesinde, müsabaka sırasında ve sonrasında stresi en yoğun yaşadıkları, antrenörlerden, sporculardan ve taraftarlardan zaman zaman çeşitli olumsuz tepkiler aldıkları da görülmektedir. Çünkü hakem; seyirci ile sporcu arasında ve aynı zamanda rakip takımlar arasında köprü görevini görmekte, öte yandan oyunun önceden belirlenmiş kurallar çerçevesinde değerlendirmesini yapmaktadır (Orta, 2000).

Öfke; engellenme, saldırıya uğrama tehdit edilme, yoksun bırakma, kısıtlama gibi durumlarda hissedilen genellikle neden olan şeye ya da kişiye yönelik şu ya da bu şekilde saldırgan davranışlarla sonuçlanabilen oldukça yoğun, olumsuz bir duygudur (Budak, 2000). Bilişsel davranışçı yaklaşıma göre öfke, biliş ve davranışın karşılıklı olarak etkilendiği, bilişsel kökenli duygusal durum olarak tanımlanmaktadır (Balkaya, 2001). İnsanları öfkelendiren nedenlerin başında engellenme (isteğin yerine gelmemesi), önemsenmeme, aşağılanma, keyfi bir davranışla karşılaşma (haksızlığa uğrama) ve saldırıya uğrama (psikolojik yönden hakarete uğrama; fizyolojik yönden bedensel saldırıya uğrama) gelir. Amaçlarına ulaşması ve ihtiyaçlarını karşılaması noktasında insanı engelleyecek durum, olay ya da kişi, öfke duygusunun oluşumunda en başta gelen nedenlerdir (Atkinson ve ark., 1996). Bu noktada önemli olan bireyin, doğru kişiye, doğru derecede, doğru zamanda, doğru amaçla ve doğru yolla öfkesini ifade edebilmesidir (Baltaş, 2005).

Empatik eğilim, doğuştan getirdiği ve yaşantılar yoluyla bir miktar geliştirebildiği kabul edilen kişiliğin bir parçası olup; kişilerin günlük davranışları içerisinde empatik davranışta bulunma potansiyelidir (Çelik ve Çağdaş, 2010). Bir kimse ile birlikte var olma şekli olan 
empatinin çeşitli görünümleri vardır. Bir kimsenin özel algısal dünyasına girmek ve onunla tümüyle beraber olmak olan empatik eğilim, sosyal duyarlılık olarak tanımlamıştır (Rogers, 1983). Empati kuracak kişi, karşısındakinin yerine kendisini koymalı ve onun gözüyle, onu bakış açısıyla olaylara bakmalı, karşısındaki kişinin duygu ve düşüncelerine karşı duyarlı olmalı ve doğru olarak anlamalı, diyalog sonunda zihninde oluşan empatik anlayışı empati kurduğu kişiye iletmelidir (Dökmen, 2008).

Sosyal duyarlılığın bir kişilik özelliği olduğunu ve her insanda bulunmadığını, sosyal duyarlılığa sahip bireylerin daha fazla empatik olabileceklerini ve empatiyi kolayca öğrenebileceklerini belirtmiştir. Nitekim öfkeden korunmayı ve azaltmayı hedefleyen bazı yaklaşımlarda etkili iletişim becerileri, sosyal beceri eğitimi, sosyal desteklerin kullanımı, empatik olma, çatışma çözümleri ve duygusal kontrolün arttırılması gibi beceriler önemsenmektedir (Lerner, 1989).

Bireylerin hayat kalitesini olumsuz yönde etkileyen yüzeysel ve başarısız ilişkiler, bireylerin birbirlerini anlayamamasına ve çatışmaların yaşanmasına neden olmaktadır. Yaşanılan çatışmaları yapıcı yollarla çözümleyebilmek ve daha nitelikli bir iletişim kurabilmek ancak bireylerin empatik becerilerini etkin bir şekilde kullanmalarıyla mümkün olabilmektedir (Kılıç, 2016). Davis'e göre empati kurabilme potansiyeli bulunan kişiler, kişiler arası iletişimde daha başarılı olmaktadırlar (Akt. Öztürk ve ark., 2004). Spor müsabakaları esnasında da öfke ve kızgınlığın kaçınılmaz olması, sağlıklı iletişim ve empatinin önemini arttırmaktadır. İnsanlar arası ilişkilerde başarıyı belirleyen ve sosyal ilişkileri yönlendiren empati kavramı toplum dokusunu koruyan önemli ve gerekli bir beceri olarak kabul edilir. Çünkü öfke normal ve sağlıklı bir duygudur. Öfkesi ve kızgınlığından ötürü insanın kendisini suçlu hissetmesi doğru değildir. Sağlıksız olan, öfkenin saldırganlığa dönüşmesidir (Akdeniz, 2007).

Müsabakalarda tüm olumsuzluklar karşısında güreş hakemlerinin öfke ve kızgınlık düzeylerini kontrol etmeleri ve duygudaşlık yaparak olaylara yaklaşması görevlerini başarıyla yerine getirmelerini sağlayacaktır. Çünkü insanlar arası ilişkilerde başarıyı belirleyen ve sosyal ilişkileri yönlendiren empati kavramı toplum dokusunu koruyan önemli ve gerekli bir beceri olarak kabul edilir. Bu kapsamda kişiler arası iletişimde öfkeli bireye empatik olarak yaklaşmak, bireyi yargılamadan, eleştirmeden anlamaya çalışmak, öfkenin kaynağına ulaşarak bireyin incinmesini önleyebileceği önemli görülmektedir (Ornstein, 1999). Bu açıdan güreş hakemlerinin de öfkelendikleri esnada davranışlarını empati kurarak duygularına yenilmeden profesyonel bir şekilde görevlerini sürdürmelerinin taraftarlar, antrenörler ve sporcular tarafından hakeme daha da güvenilmesine olumlu katkı sağlayacaktır (Sülün, 2013).

Literatürde öfke kontrolü, öfke ve kızgınlık düzeyleri ile empatik eğilim arasında ilişkiyi çeşitli disiplinlerde inceleyen (Akdeniz, 2007; Baygöl, 1997; Danışık ve Baker, 2005; Gökler, 2009; Rehber, 2007; Sala, 1997; Öz, 1998; Tambağ ve Öz, 2004) çalışmaların bir hayli mevcut olduğu ancak spor hakemlerinin öfke ve kızgınlık düzeyleri ile empatik eğilim gösterme düzeylerini inceleyen çalışmaların (Demirkıran, 2003; Satman, 2014; Sülün, 2013; 
Zorba ve ark., 2016) sınırlı sayıda kaldığı görülmektedir. Erkek güreş hakemlerinin öfke ve kızgınlık düzeyleri ile empatik eğilim düzeyleri arasındaki ilişkiyi inceleyen bu çalışmanın da alana katkı sağlayacağı düşünülmektedir. Çalışmanın amacı, erkek güreş hakemlerinin öfke ve kızgınlık düzeyleri ile empatik eğilim düzeyleri arasındaki ilişkiyi çeşitli değişkenlere göre incelemektir. Çalışmada şu sorulara yanıt aranmıştır;

1- Erkek güreş hakemlerinin öfke ve kızgınlık ile empatik eğilimleri hangi düzeydedir?

2- Erkek güreş hakemlerinin öfke ve kızgınlık düzeyleri ile empatik eğilim düzeyleri arasında cinsiyet, medeni durum, yaş, eğitim, hakemlik y1l, hakemlik kategorisi ve başka mesleğe sahip olup olmama değişkenlerine göre anlamlı bir ilişki var mıdır?

\section{YÖNTEM}

\section{Araştırma Modeli}

Erkek güreş hakemlerinin öfke ve kızgınlık düzeyleri ile empatik eğilim düzeyleri arasındaki ilişkiyi çeşitli değişkenler açısından inceleyen bu çalışma, genel tarama modelinde ilişkisel nitelikte bir araştırmadır.

\section{Çalışma Grubu}

Araştırmanın çalışma grubunu, 27-30 Aralık 2016 tarihinde Antalya Kemer'de düzenlenen Türkiye Güreş Federasyonu- güreş hakemleri eğitim seminerine katılan 88 erkek güreş hakemi oluşturmaktadır

\section{Veri Toplama Aracı}

Araştırmanın verileri ölçeğin orjinali Spielberger (1983, The State Trait Anger Scale-STAS) tarafından geliştirilmiş, Türkçe uyarlaması ise Özer (1994) tarafından Türkçeye uyarlanan "Sürekli Öfke-Öfke Tarz Ölçeği [SÖ-ÖTÖ]" ile Dökmen (1988) tarafindan geliştirilen "Empatik Eğilim Ölçeğì" ile toplanmıştır.

Sürekli Öfke-Öfke Tarz Ölçeği toplam 4 alt boyuttan ibaret olup 34 maddeden oluşmaktadır. Ölçeğin alt boyutlarında Cronbach Alfa güvenirlik katsayısı 0.62 ile 0.84 arasında bulunmuştur. Mevcut araştırmada ise ölçek 34 madde ile tek boyutlu olarak gözlenmiş, Cronbach Alfa güvenirlik katsayısı 0.74 olarak hesaplanmıştır. Ölçek; 1: Hiç, 2: Biraz, 3: Oldukça, 4: Tümüyle olmak üzere 4'lü likert tipinde derecelendirmeye sahiptir. Ölçekten alınabilecek en düşük puan 33 , en yüksek puan ise 132 'dir.

Diğer bir ölçek olan "Empatik Eğilim Ölçeği" 5' li Likert türünde olup 20 maddeden oluşmaktadır. Maddeler; 1: Tamamen Aykırı, 2: Oldukça Aykırı, 3: Kararsızım, 4: Oldukça Uygun, 5: Tamamen Uygun olarak derecelendirilmiştir. Ölçeğin Cronbach Alfa güvenirlik katsayısı 0.91 olarak bulunmuştur. Mevcut araştırmada ise ölçeğin Cronbach Alfa güvenirlik katsayıs1 0.77 olarak hesaplanmıştır. Ölçek maddelerinin yaklaşık yarısı, katılımcıların evet deme eğilimlerini önlemek için negatif olarak yazılmıştır. Ölçekte yer alan; 3, 6, 7, 8, 11, 12, 13 , ve 15. maddeler negatif ifadeler olup, ters puanlanmıştır. 


\section{Verilerin Analizi}

Verilerin çözüm ve yorumlanmasında, öfke ve kızgınlık ile empatik eğilim düzeyleri arasındaki ilişkinin analizi için "pearson momentler çarpımı korelasyon katsayısı", öfke ve kızgınlık düzeyi yordamasına ilişkin "empatik eğilim gösterme düzeyi, medeni durum, yaş, eğitim durumu, hakemlik yıll, hakemlik kategorisi ve hakemlik dışı başka mesleğe sahip olup olmama durumuna" çoklu regreasyon analizi uygulanmıştır. Bulguların yorumlanmasında anlamlılık düzeyi için $\mathrm{p}<0.05$ değeri baz alınmıştır.

\section{BULGULAR}

Katılımcıların demografik özelliklerine ilişkin dağılımlar tablo 1' de sunulmuştur.

Tablo 1. Katılımcıların demografik özelliklerine ilişkin dağılımları

\begin{tabular}{lcc}
\hline Medeni Durum & $\mathbf{n}$ & $\mathbf{\%}$ \\
\hline Bekâr & 15 & 17.0 \\
Evli & 73 & 83.0 \\
\hline Yaş & 10 & 11.4 \\
\hline 18-27 Yaş & 33 & 37.5 \\
28-37 Yaş & 33 & 37.5 \\
38-47 Yaş & 12 & 13.6 \\
48 ve Üzeri & & \\
\hline Eğitim & 3 & 3.4 \\
\hline Lise & 58 & 65.9 \\
Lisans & 27 & 30.7 \\
Lisansüstü & & \\
\hline Hakemlik Yllı & 13 & 14.8 \\
\hline 1-4 Y1l & 20 & 22.7 \\
5-8 Y1l & 15 & 17.0 \\
9-12 Y11 & 17 & 19.3 \\
13-16 Y11 & 23 & 26.1 \\
17 Y1l ve Üstü & & \\
\hline Hakemlik Kategorisi & 59 & 67.0 \\
\hline Milli hakem & 9 & 10.2 \\
Uluslararası 3 kademe & 11 & 12.5 \\
Uluslararas1 2 kademe & 9 & 10.2 \\
Uluslararası 1 kademe & & 89.8 \\
\hline Başka Meslek & 79 & 10.2 \\
\hline Evet & 9 & 100.0 \\
Hayır & 88 & \\
\hline Toplam & & \\
\hline & & \\
\hline
\end{tabular}

Tablo 1'e göre; medeni durum olarak hakemlerin \% 17,0 (15 kişi) bekar, \% 83,0 (73 kişi) evlidir. Yaş aralığı olarak hakemlerin; \% 11,4'ü (10 kişi) 18-27 arası, \% 37,5'i (33 kişi) 2837 arası ve 38-47 arası yaşa sahiptir. 48 ve üzeri yaş aralığına sahip hakemlerin ise \% 13,6 (12 kişi) olduğu görülmektedir.

Hakemlerin eğitim düzeyleri incelendiğinde ise \% 65,9 'unun (58 kişi) lisans, \% 30,7 (27 kişi) lisansüstü ve \% 3,4'ünün (3 kişi) lise düzeyinde eğitime sahip oldukları görülmektedir. Hakemlerin büyük çoğunluğu $(\% 81,8)$ lisans ve lisansüstü eğitim mezunudur. Hakemlerin meslekteki çalışma yılları incelendiğinde, 1-4 yıl arası \% 14,8 (13 kişi), 5-8 yıl arası \%22,7 (20 kişi), 9-12 yıl arası \% 17,0 (15 kişi), 13-16 yıl arası \% 19,3 (17 kişi) ve 17 yıl üstü \% 26,1 (23 kişi) oldukları görülmektedir. Yine tablo 1' e göre; hakemlerin \% 67,0'i (59 kişi) Milli Hakem, \% 10,2'si (9'ar kişi) Uluslararası 3. ve 1. Kademe Hakemi, \%12,5'i (11 kişi) 
Uluslararası 2 Kademe Hakemi oldukları tespit edilmiştir. Hakemlerin \% 89,8'i (79 kişi) hakemlik dışında başka mesleği de icra ettikleri, \% 10,2'sinin (9 kişi) ise sadece hakemlik yaptıkları belirlenmiştir.

Tablo 2. Hakemlerin öfke ve kızgınlık düzeyleri ile empatik eğilim gösterme düzeyleri arasındaki ilişkinin korelasyon analizi

\begin{tabular}{lccc}
\hline Değişken & N & r & p \\
\hline $\begin{array}{l}\text { Öfke ve Kızgınlık } \\
\text { Empatik Eğilim Gösterme }\end{array}$ & 88 & 0.18 & 0.08 \\
\hline
\end{tabular}

Tablo 2' ye göre erkek güreş hakemlerinin, öfke ve kızgınlık düzeyleri ile empatik eğilim gösterme düzeyleri arasında istatistiksel açıdan anlamlı bir ilişki saptanmamıştır ( $p>0.05)$.

Tablo 3. Hakemlerin öfke ve kızgınlık düzeylerinin yordanmasına ilişkin çoklu regresyon analizi sonuçları (enter metodu)

\begin{tabular}{lccccccc}
\hline & $\mathbf{B}$ & $\mathbf{S H}_{\mathbf{B}}$ & $\boldsymbol{\beta}$ & $\mathbf{T}$ & $\mathbf{p}$ & İkili r & Kısmi r \\
\hline Sabit & 50.59 & 10.21 & & 4.95 & 0.00 & & \\
Empatik Eğilim & 0.14 & 0.12 & 0.14 & 1.22 & 0.23 & 0.15 & 0.14 \\
Medeni Durum & -1.20 & 2.47 & -0.06 & -0.49 & 0.63 & 0.00 & -0.05 \\
Yaş & 2.49 & 1.45 & 0.27 & 1.72 & 0.09 & 0.16 & 0.19 \\
Eğitim & 1.39 & 1.73 & 0.09 & 0.81 & 0.42 & 0.06 & 0.09 \\
Hakemlik Y1lı & -0.80 & 0.88 & -0.14 & -0.91 & 0.37 & 0.09 & -0.10 \\
Hakemlik Kategorisi & 0.27 & 0.87 & 0.04 & 0.31 & 0.76 & 0.08 & 0.03 \\
Başka Meslek & 5.08 & 2.87 & 0.19 & 1.77 & 0.08 & 0.18 & 0.19 \\
\hline
\end{tabular}

$\mathrm{r}=0,30 ; \mathrm{r}^{2}=0,09 ; \mathrm{f}=1,18 ; \mathrm{p}=0,35$

Tablo 3'e göre; hakemlerin medeni durumu, yaşları, eğitim durumları, hakemlik yılı, hakemlik kategorileri ve başka meslek icra edip etmemeleri ile empatik eğilimleri, öfke ve kızgınlık düzeyleri ile anlamlı bir ilişki vermemektedir $\left(r=0,30 ; r^{2}=0,09, p>0.05\right)$. Bir başka ifade ile hakemlerin demografik değişkenleri öfke ve kızgınlık düzeylerini anlamlı olarak yordamamaktadir.

\section{TARTIŞMA VE SONUÇ}

Erkek güreş hakemlerinin öfke ve kızgın-kızgınlık düzeyleri ile empatik eğilim düzeyleri arasındaki ilişkinin incelendiği bu çalışmada; hakemlerin öfke ve kızgınlık düzeyleri ile empatik eğilim gösterme düzeyleri arasında anlamlı bir ilişki saptanmamıştır. Bu sonuca göre güreş hakemlerinin medeni durumları, yaşları, eğitim durumları, hakemlik yılları ve hakemlik dışı başka meslek icra edip etmeme değişkenleri ile empatik eğilimlerinin öfke ve kızgınlık düzeyleri de anlamlı bir ilişki vermemektedir. Alan yazında yapılan çalışmalar incelendiğinde; Sülün (2013), futbol hakemlerinin öfke ve kızgınlık düzeyleri ile empatik eğilim düzeylerini karşılaştırdığı çalışmasında, hakemlerin öfke eğilimleri ile empati ilişkileri arasında anlamlı bir farkın olmadığını belirlemiş, hakemlerin hangi seviyede hakemlik yaptıkları, yıl değişkenine göre, eğitim düzeylerine göre, mesleki düzeylerine göre, hakemlik kariyerlerine göre, sürekli öfke ve öfke ile empatik eğilim düzeyleri açısından anlamlı bir ilişkinin olmadığını saptamıştır.

Yine Zorba ve ark. (2016)' nın, futbol hakemlerinin müsabaka öncesi sürekli kayg1 düzeylerini bazı değişkenlere göre inceledikleri çalışmalarında, müsabaka öncesi sürekli 
kaygı düzeyi bakımından cinsiyet değişkenine, hakemlik kategorilerine ve hakemlik yapma sürelerine göre hakemlerde anlamlı bir farkın olmadığını belirtmişlerdir. Kolayiş ve ark., (2002), çalışmalarında, hakemlik yaşı ile kaygı arasında anlamlı bir farkın olmadığını, Satman (2014), hakemlerin sesli ve sessiz ortamlarda verdikleri kararlar arasında genel olarak anlamlı bir farklılık olmadığını rapor etmişlerdir.

Kargün (2011), Futbol hakemlerinin iş tatmini ve mesleki tükenmişlik düzeylerini çeşitli faktörler açısından incelediği çalışmasında, klasman futbol hakemlerinin yaşlarına, medeni durumlarına, mesleklerine, aylık ortalama gelirlerine, eğitim düzeylerine, hakemlikteki kategorisine, hakemliğin maddi getirisine, hakemliğin sosyal statüsüne, görev alma durumlarına, farklı branşlarda hakemlik yapma durumlarına ve hakemliğin asli mesleğini etkileme durumlarına göre iş doyum düzeyleri ile mesleki tükenmişlik düzeylerinin bütün alt boyutları (duyarsızlaşma, duygusallık, kişisel başarı) arasında anlamlı bir ilişkinin olmadığını belirtmiştir. Öztürk ve ark., (2004), çalışmalarında bireysel ve takım sporları hakem ve antrenörlerinin empati puanları arasında önemli bir farklılığın olamadığını, katılımcıların eğitim durumlarının, hakem veya antrenör olarak görev yapma sürelerinin ve mesleklerinin empatik yaklaşımlarını etkilemediğini saptamışlardır. Bu bulgular çalışmamızın bulgularını destekler niteliktedir.

Alan yazında farklı sonuçların elde edildiği çalışmalar da mevcuttur. Castagna ve ark., (2007), hakemlerin müsabaka esnasında psikolojik stres altında olduklarını, Weston ve ark., (2011) ise hakemlerin psikolojik stresleri ile birlikte fiziksel stresi de ortaya koydukların belirtmişlerdir. Can ve ark., (2011), çalışmalarında futbol hakemlerinin çalışma süreleri arttıkça yaşadıkları stres düzeyinin düştüğü sonucuna ulaşmışlardır. Rainey ve Hardy (1999), çalışmalarında genç ve deneyimsiz olan hakemlerin müsabaka öncesinde daha fazla kaygı ve stres yaşadıklarını belirtirken, Sülün (2013) çalışmasında, hakemlerin hangi seviyede hakemlik yaptıklarına göre empatik eğilim düzeyleri, arasında anlamlı bir farkın olmadığını saptamıştır. Zorba ve ark., (2016) ile Arslanoğlu ve ark., (2010) çalışmalarında, hakemlik kategorisi değişkeni ile hakemliklerin sürekli kaygı puanları arasında istatistiksel olarak anlamlı bir farkın olmadığını rapor etmişlerdir.

Örneklem grubunu Türkiye Güreş Federasyonu- güreş hakemleri eğitim seminerine katılan erkek güreş hakemlerinin oluşturduğu bu çalışmanın sonucunda; çalışmanın kadın güreş hakemlerinin de dahil edileceği daha geniş bir örneklem grubu üzerinde yürütülmesi, farklı spor branşı hakemleri ile çalışmanın yapılarak verilerin karşılaştırılması, hakem eğitim seminerlerinde bu alanda yapılmış çalışma bulguları ışı̆̆ında uzman kişilerce hakemlerin öfke ve kızgınlık düzeylerini kontrol etmelerine ve empatik eğilim göstermelerine yönelik özel eğitimler verilmesi çalışmamızın önerileri olarak getirilmektedir. 


\section{KAYNAKLAR}

Akdeniz, M. (2007). Öfke kontrolü ĕgitiminin lise ögrencilerinin öfke kontrolü becerilerine etkisi. Yayımlanmamış Yükseklisans Tezi, Çukurova Üniversitesi Sosyal Bilimler Enstitüsü, Adana.

Arslanoğlu, E., Tekin, M., Arslanoğlu, C. ve Özmutlu, İ. (2010). Voleybol hakemlerinin çeşitli değişkenlere göre kaygı ve temel psikolojik ihtiyaç düzeylerinin incelenmesi. Uluslararası Insan Bilimleri Dergisi, 7(2), 985-995.

Atkınson, R.L., Smith, E.E., Bem, D.J., \& Nolen-Hoeksema, S. (1996). Hilgard's introduction to psychology. New York: Harcourt Brace Company.

Balkaya, F. (2001). Öfke: Temel boyutları nedenleri ve sonuçları. Türk Psikoloji Yazıları, 4 (7), 21-45.

Baltaş, A. (2005). Ekip çalışması ve liderlik. İstanbul: Remzi Kitabevi.

Baygöl, E. (1997). Ergenin öfke tepkilerinin incelenmesi. Yayımlanmamış Yüksek Lisans Tezi, Uludağ Üniversitesi, Sosyal Bilimler Enstitüsü, Bursa.

Budak, S. (2000). Psikoloji sözlüğ̈̈. Ankara: Bilim ve Sanat Yayınları.

Can, Y., Soyer, F., Çoban, Ü. (2011). Negatif duygusallığın stres üzerindeki etkisi: Faal futbol hakemleri üzerinde bir araştırma. Niğde Üniversitesi Beden Eğitimi ve Spor Bilimleri Dergisi, 5(2), 165-174.

Castagna, C., Abt, G. \& D’Ottavio, S. (2007): Physiological aspects of soccer refereeing performance and training. Sports Medicine 37(7), 625-646.

Cel, A. (1994). Hakemlik psikolojisi, (Çev: Ayşe Kin). Futbol Bilim ve Teknoloji Dergisi, 1, 21-23.

Cicioğlu, İ. (2001). Türk güreş hakemliğinin bugünkü durumu, 1. Türk Güreş Kurultayı, 6-7 Ocak 2001, BelekAntalya.

Çelik, E., ve Çağdaş, A. (2010). Okul öncesi eğitim öğretmenlerinin empatik eğilimlerinin bazı değişkenler açısından incelenmesi. Selçuk Üniversitesi, Sosyal Bilimler Enstitüsü Dergisi, 23, 9.

Danışık, N.D., ve Baker, Ö.E. (2005). Ergenlerde sürekli öfke-öfke ifade tarzları ve problem çözme. Psikiyatri Psikoloji Psikofarmakoloji (3P) Dergisi, 13 (3), 161-167.

Decker, W. (1992). Sports and games of ancient Egypt. (Çeviri: A. Guttmann), Yale University Press: New Haven.

Demirkıran, S. (2003). Futbol fanatizmi: Taraftar kimliği, öfke ve saldırganlık ĕğilimleri arasındaki bă̆lantılar. Yayımlanmamış Yüksek Lisans Tezi, Ankara Üniversitesi, Sosyal Bilimler Enstitüsü, Ankara.

Dökmen Ü. (1988). Empatinin yeni bir modele dayanarak ölçülmesi ve psikodrama ile geliştirilmesi. Ankara Üniversitesi Eğitim Bilimleri Fakültesi Dergisi, 21(1-2), 155-190.

Gökler, R. (2009). Empatik eğilim ölçeğinin ilköğretim sekizinci sınıflar için uyarlanması. Aile ve Toplum Eğitim - Kültür ve Araştırma Dergisi, 5(19), 77-86.

Kargün, M. (2011). Futbol hakemlerinin iş tatmini ve mesleki tükenmişlik düzeylerinin çeşitli faktörler açısından incelenmesi. Yayımlanmamış Yüksek Lisans Tezi, İnönü Üniversitesi Sağlık Bilimleri Enstitüsü, Malatya.

Kılıç, A. (2016). Turizm işletmeciliği ve otelcilik anabilim dalı turist rehberlerinde empatik ĕgilim ve çatışma çözme davranışı ilişkisi. Yayımlanmamış Yükseklisans Tezi, Balıkesir Üniversitesi Sosyal Bilimler Enstitüsü, Balıkesir. 
Kolayiş, H., Taşkıran, Y., Ulusoy, Y., Sertbaş, K., ve Gönener, A. (2002). Marmara bölgesi A, B ve C klasmanı futbol hakemlerinin kaygı seviyelerinin reaksiyon zamanı ile ilişkisi, 7. Uluslararası Spor Bilimleri Kongresi, 27-29 Ekim 2002, Antalya.

Lerner, H. (1989). The Dance of anger: A woman's guide to changing the patterns of intimate relationships. New York: Harper and Row Publishers.

Ornstein, P.H. (1999). Conceptualization and treatment of rage in self psychology. Journal of Clinical Psychology/In Session: Psychotherapy in Practice, 55, 283-293.

Orta, L. (2000). Dünya'da ve Türkiye'de futbol hakemliğinin başlangıcı ve gelişimi semineri, Onsekiz Mart Üniversitesi, Beden Eğitimi ve Spor Bölümü, Çanakkale

Öz, F. (1998). Son sınıf hemşirelik öğrencilerinin empatik eğilimleri, empatik becerileri ve akademik başarıları arasındaki ilişki. Cumhuriyet Üniversitesi Hemşirelik Yüksekokulu Dergisi, 2(2), 32-38.

Öztürk, F., Koparan, Ş., Haşıl, N., Efe, M. ve Özkaya, G. (2004). Antrenör ve hakemlerin empati durumlarının araştırılması. SPORMETRE Beden Ë̆itimi ve Spor Bilimleri Dergisi, 2(1), 19-25.

Pehlivan, Z. ve Demir, A. (2006). Türk kültüründe güreş ve pehlivanlık imgesi, Uluslararası II. Tarihi Kırkpınar Sempozyumu Bildirileri, Edirne Trakya Üniversitesi, 2-4 Temmuz.

Petrov, R. (1994). Olimpic wrestling throughout the millennia. Colorado Springs: IAWF, Printing \& Publishing Distributing Co. Ltd. H-1037, 107-108.

Rainey, D., Hardy, L. (1999). Sources of stress, burnout and intention to terminate among rugby union referees. Journal of Sports Sciences, 17, 797-806.

Rehber, E. (2007). Illköğretim ikinci kademe öğrencilerinin empatik ĕgilim düzeylerine göre çatışma çözme davranışlarının incelenmesi. Yayınlanmamış Yükseklisans Tezi, Çukurova Üniversitesi, Sosyal Bilimler Enstitüsü, Adana.

Rogers, C.R. (1983). Empatik olmak değeri anlaşılmamış bir varoluş şeklidir [Be empathic is a way of being undigested value], (Çev: Füsun Akkoyun) A.̈̈. Eğitim Bilimleri Fakültesi Dergisi, 16(1), 103-124.

Sala, G. (1997). Zonguldak Karaelmas Üniversitesi öğrencilerinin öfke ifade etme biçimlerinin incelenmesi. Yayımlanmamış Bilim Uzmanlığı Tezi, Hacettepe Üniversitesi Sağlık Bilimleri Enstitüsü, Ankara.

Satman, C. (2014). Futbol maçlarındaki seyirci topluluklarının sesinin, hakemlerin kararları üzerindeki etkisi. Ankara Üniversitesi Spor Bilimleri Fakültesi Dergisi, 12 (2), 147-154.

Sülün, Ö. (2013). Futbol hakemlerinin öfke ve kızgınlık düzeyleri ile empatik ĕgilim düzeylerinin karşılaştırılması. Yayımlanmamış Yükseklisans Tezi, Karamanoğlu Mehmetbey Üniversitesi Sosyal Bilimler Enstitüsü, Karaman.

Tambağ, H. ve Öz, F. (2004). Aileleri ile birlikte ve yetiştirme yurtlarında yaşayan ergenlerin öfke ifade etme biçimleri. Kriz Dergisi, 1, 11-21.

Vikipedi (2017). https://tr.wikipedia.org/wiki/Güreş, Erişim Tarihi: 12.02.2017

Weston, M., Drust, B., \& Gregson, W. (2011). Intensities of exercise during match-play in FA Premier League referees and players. Journal of sports sciences, 29(5), 527-532.

Zorba, E., Göksel, A.G., Pala, A. ve Zorba, N. (2016). Futbol hakemlerinin müsabaka öncesi sürekli kayg1 düzeylerinin bazı değişkenlere göre incelenmesi (Ege Bölgesi Örneği). Ankara Üniversitesi Spor Bilimleri Fakültesi Dergisi, 14 (2), 175-181. 